The Journal of Animal \& Plant Sciences, 30(3): 2020, Page: 537-544

ISSN (print): 1018-7081; ISSN (online): 2309-8694

\title{
HERITABILITY ESTIMATES OF SOME BODY MEASUREMENTS IN NILI RAVI BUFFALOES
}

\author{
R. H. Mirza ${ }^{* 1}$, M. A. Khan², A. Waheed ${ }^{1}$, M. Akhtar ${ }^{3}$, S. M. Raihan- dilshad ${ }^{4}$, Asim Faraz ${ }^{1}$, H. M. Ishaq ${ }^{1}$ and \\ Z. H. Kuthu
}

\begin{abstract}
${ }^{1}$ Department of Livestock and Poultry Production, Faculty of Veterinary Sciences, Bahauddin Zakariya University, Multan, Pakistan; ${ }^{2}$ Department of Breeding and Genetics, Faculty of Animal Production and Technology, Cholistan University of Veterinary and Animal Sciences, Bahawalpur- 63100, Pakistan; ${ }^{3}$ Buffalo Research Institute, Pattoki-55300, (Punjab), Pakistan; ${ }^{4}$ Department of Theriogenology, Faculty of Veterinary and Animal Sciences, Gomal University, Dera Ismail Khan-29220, Pakistan; ${ }^{5}$ Faculty of Veterinary Sciences, University of Poonch, Rawalakot

*Corresponding author's email: riazmirza71@yahoo.com

The paper was presented in International Buffalo Congress 2019, February 18-20, Lahore, Pakistan
\end{abstract}

\begin{abstract}
Current study was conducted to find out heritability estimates of some body measurements of Nili Ravi buffaloes maintained at 5 Livestock Experiment Stations in Punjab Pakistan. Recording of body measurements was continued for 3 years since 2010 to 2012. Heritabilities of traits were estimated using BLUP (Best Linear Unbiased Prediction) evaluation techniques. Influencing factors such as age of the buffalo at scoring, stage of lactation, parity, herd and season were included in the model. Individual Animal Model was fitted under Restricted Maximum Likelihood (REML) Procedure. Data were analysed using the mixed model procedure of the Statistical Analysis Systems. Fixed effects observed to be significant in the initial analysis were included in the model for estimation of variance components from which genetic parameters were estimated. The ASREML set of computer programs was used to estimate heritabilities. Least squares means for head length, poll width, horn diameter, ear length, ear width, neck circumference, neck length, bodylength, tail length, tail diameter, height at sacrum and rump length were found as $54.13 \pm 3.48,30.95 \pm 2.35$, $18.65 \pm 2.06,29.5 \pm 2.12,18.66 \pm 1.22,95.77 \pm 8.58,53.32 \pm 4.56,139.56 \pm 6.29,103.51 \pm 12.55,22.41 \pm 2.00,135.77 \pm 4.40$, $43.52 \pm 2.58 \mathrm{~cm}$ respectively. Results from univariate analysis of body measurement traits showed that most of the body measurements were low to moderate in heritablility. Overall range of heritability estimates for body measurements was found as $0.03 \pm 0.06$ for neck circumference to $0.41 \pm 0.09$ for tail length. Head length, tail length, tail diameter at base and ear length showed reasonably high estimates of heritability. The breeders preference for buffaloes with relatively smart head, thin tail and longer tail is supported through current study and these traits can be included for selection decisions for the production of replacement stock.
\end{abstract}

Key words: body measurements, heritability, Nili Ravi buffalo, variance components https://doi.org/10.36899/JAPS.2020.3.0063

Published online March 25, 2020

\section{INTRODUCTION}

Morphological evaluation of different breeds of dairy cattle and buffaloes is still considered important from selection point of view. For proper use of morphological traits in selection programs, the knowledge of their descriptive statistics and genetic parameters are necessary. Such information is needed for management of animal genetic resources at global levels (FAO, 2012). Khan et al., (2007) has reported Nili Ravi a unique animal genetic resource of Pakistani farming system. There are certain body characters and features of every breed that distinguish it from other breeds and animals. Knowledge of these characters helps in further breeding and improvement programs of breeds. The characters like that are considered important for description include height and length of the animal, head shape and neck conformation, tail length and thickness at base, ear length and width and rump length and horn shape. These characteristics are considered important features of buffaloes. In case of Nili Ravi buffaloes, horn shape is very much emphasized and animals with hook shaped horns fetch more prices at market level.

The buffaloes both Swamp and Riverine have been characterized on the basis of physical features by different scientists. The focus of the studies was limited to a few body measurement traits. A few studies have been performed on Pakistani buffalo (Nili-Ravi breed). The main focus of the studies conducted by Phangchung and Roden (1996) for crossbred buffaloes of Bhutan, Prasad and Kumar (2005) for Tarahi buffalo breed and Sahu et al. (2017) for Indian buffalo (Sambalpuri) has been phenotypic characterization. The study of Mehboob (1996) focused on phenotypic correlation of body measurements with milk production. A very few studies have reported gentic parameters for buffalo body measurement traits. The genetic parameetrs particularly 
heritability of the trait is required for genetic improvement of animals through selective breeding.

A lot of literature is available on different dairy cattle breeds in the world but information on this aspect of buffalo breeds is very limited. The same has been pointed out in a published book on buffaloes "Buffalo the Animal of Future" that the information on the body measurements of buffaloes in Pakistan is scanty (Khan, 2009). This emphasized the need for studies on Nili Ravi buffaloes. With this back ground in mind the current study was planned. The study aimed at to characterize Nili-Ravi buffaloes in terms of morphology, to quantify the magnitude of fixed effects like herd, stage of lactation, parity and age of animal at recording affecting body measurement traits and heritability estimation of body measurement traits of Nili-Ravi buffaloes of Pakistan.

\section{MATERIALS AND METHODS}

The data consisted of body measurements of the buffaloes mainted at institutional herds of the Punjab province including Livestcock Experiment Station, Bhunikey, Pattoki, Livestcock Experiment Station, Chack Katora Hasilpur, Livestcock Experiment Station, Haroonabad, Livestcock Experiment Station, Khushab and Livestcock Experiment Station, Rakh Ghulaman, Kalurkot. The major recorded population of buffalo is being maintained at these Livestock Experiment Stations. The pedigree records of these animals were maintained routinely at the farms.
The feeding, breeding and housing practices at all these farms were similar. Such information included that animals were housed in open sheds. The animals were sent for grazing in the morning and chaffed fodder was fed in the evening. The winter fodder included legumes like berseem and sarson and cereals like oat fodder. The summer fodders consisted of mainly grasses like sorghum and sudan-sorghum hybrid, maize and Jantar were offered. The lactating buffaloes were supplemented with mixed ration depending on daily milk yield. As a thumb rule $1 \mathrm{~kg}$ of mix ration was fed for every $3 \mathrm{~kg}$ of milk produced by the buffalo. Additional minerals specially common salt was offered in manger as a lick.

Data collection: Body measurements were recorded on 437 lactating buffaloes through year 2010 to 2012. The measurmeents were recorded three times during the course of lactation period. The first record was made at 15 to 90 days after date of calving, second measurement was made at 91 to 180 days after calving and third meaurment was made at 181 to 270 days after calving. The buffaloes were restrained in the cattle crush and all the measurements were made during day time from 7 am through $3 \mathrm{pm}$. The traits measured and their description is tabulated in Table 1.

The information regarding animal identification, ancestory, birth date, calving date, parity, age of buffalo at classification was collected from the records available at the farm.

\section{Table 1. Body points and their description for Nili Ravi buffaloes}

\begin{tabular}{lll}
\hline Sr. No & Trait & Description \\
\hline 1 & Head length $(\mathrm{cm})$ & From the centre of the poll to the muzzle \\
2 & Poll width $(\mathrm{cm})$ & The distance between base of horns \\
3 & Horn diameter $(\mathrm{cm})$ & Horn diameter measured around the base of the horn with measuring tape \\
4 & Ear length $(\mathrm{cm})$ & Start of the ear to its tip holding ear at right angle of the body surface \\
5 & Ear width $(\mathrm{cm})$ & Width of the ear from outside at the centre \\
6 & Neck circumference $(\mathrm{cm})$ & At the centre of the neck \\
7 & Neck length $(\mathrm{cm})$ & Horizontal distance measured from first thoracic vertebra to the centre of poll while \\
& & animal standing in normal position with straight neck
\end{tabular}

Evaluation Model: The fixed effect model was fitted to find out the factors influencing the body points. The model included season, herd, parity, and stage of lactation as fixed effect and linear and quadratic effect of age of buffalo at measurement day was added as covariable. The pedigree records were traced back to five generations. There were total 1180 records on 437 buffaloes. These buffaloes were the progeny of 88 sires and 303 Dams. Number of animals with no pedigree records were 119 which were base population. Separate data and pedigree files for each trait were prepared in excel sheets.

The year was divided into five seasons as defined by Mirza et al. (2015). The other factors were herd (1-5), parity (1-4). The $4^{\text {th }}$ level included buffaloes with fourth and later parity. Satge of lactation was 
divided into four levels (early mid and late lactation and dry stage). Data were analysed using the mixed model procedure of the Statistical Analysis Systems (SAS, 2011). The factors affecting the body points significantly were inluded in animal model for estimation of variance component with Restricted Maximum Likelihood (REML) procedure outlined by Patterson and Thompson (1971). The ASREML Version (3.0) was the computer software used for this purpose (Gilmour et al., 2009). The individual animal model for estimation of animal variance was assumed as follows:

Where,

$$
\mathrm{Y}_{\mathrm{ijk}}=\mu+\mathrm{F}_{\mathrm{i}}+\mathrm{A}_{\mathrm{j}}+\mathrm{Pe}+\mathrm{e}_{\mathrm{ijk}}
$$

$\mathrm{Y}_{\mathrm{ijk}}=$ measurement of a particular trait:

$\mu=$ population mean;

$F_{i}=$ fixed effects observed to be significant from the initial analyses

$A_{j}=$ random additive genetic effect of $j^{\text {th }}$ animal with mean zero and variance $\sigma^{2} \mathrm{~A}$

$\mathrm{P}_{\mathrm{e}}=$ random permanent effect of $\mathrm{j}^{\text {th }}$ animal with mean zero and variance $\sigma^{2}$ pe $\mathrm{e}_{\mathrm{ijk}}=$ random error associated with each observation The heritability was estimated by the following formula: Heritability $\left(h^{2}\right)=\sigma_{\mathrm{A}}^{2} / \sigma_{\mathrm{P}}^{2}$

\section{RESULTS}

Least square means for body measurements: There were total 1180 observations on 437 buffaloes. These buffaloes were the progeny of 88 sires and 303 dams. There were 119 base animals with no pedigree records. The least square means $\pm \mathrm{SD}$, co-efficient of variation and ranges for different body measurements are presented in table 2. The head of the animal is very important for characterization of animals of any breed. The coefficient of variation indicates the variation that exists in a trait. For most of the traits included in the study the coefficient of variation was small which indicates very small variation. However the coefficient of variation for tail length, horn diameter at base, neck circumference, neck length and tail diameter at base were high indicating that much variation exist among the animals.

Table 2. Least squares means for body measurements in Nili Ravi buffaloes

\begin{tabular}{|c|c|c|c|c|c|}
\hline S.No & Trait & $\mathbf{N}$ & Mean \pm StdDev & $\begin{array}{l}\text { Coefficient of } \\
\text { Variation (\%) }\end{array}$ & Range \\
\hline 1. & Head length(cm) & 1179 & $54.13 \pm 3.48$ & 6.43 & $45-70$ \\
\hline 2. & Poll width $(\mathrm{cm})$ & 1172 & $30.95 \pm 2.35$ & 7.61 & $23-40$ \\
\hline 3. & Horn diameter at base $(\mathrm{cm})$ & 1178 & $18.65 \pm 2.06$ & 11.04 & $13.5-26$ \\
\hline 4. & Ear length(cm) & 1179 & $29.5 \pm 2.12$ & 7.18 & $16-37$ \\
\hline 5. & Ear width $(\mathrm{cm})$ & 1179 & $18.66 \pm 1.22$ & 6.52 & $14-23$ \\
\hline 6. & Neck circumference $(\mathrm{cm})$ & 1175 & $95.77 \pm 8.58$ & 8.96 & $52-124$ \\
\hline 7. & Neck length (horizontal) (cm) & 1088 & $53.32 \pm 4.56$ & 8.55 & $40-69$ \\
\hline 8. & Body length $(\mathrm{cm})$ & 1176 & $139.56 \pm 6.29$ & 4.51 & $118-160$ \\
\hline 9. & Tail length $(\mathrm{cm})$ & 952 & $103.51 \pm 12.55$ & 12.12 & $63-148$ \\
\hline 10. & Tail diameter at base $(\mathrm{cm})$ & 1178 & $22.41 \pm 2.00$ & 8.95 & $16-31$ \\
\hline 11. & Height at sacrum & 1179 & $135.77 \pm 4.40$ & 3.24 & $121-151$ \\
\hline 12. & Rump length(cm) & 1179 & $43.52 \pm 2.58$ & 5.93 & $36-52$ \\
\hline
\end{tabular}

Table 3 Heritability estimates of body measurements in Nili Ravi buffaloes

\begin{tabular}{clll}
\hline S.No & Traits & $\mathbf{N}$ & $\mathbf{h}^{2} \pm \mathbf{S E}$ \\
\hline 1. & Head length & 1168 & $0.25 \pm 0.091$ \\
2. & Poll width & 1161 & $0.14 \pm 0.09$ \\
3. & Horn diameter at base & 1168 & $0.16 \pm 0.09$ \\
4. & Ear length & 1168 & $0.38 \pm 0.04$ \\
5. & Ear width & 1168 & $0.06 \pm 0.09$ \\
6. & Neck circumference & 1079 & $0.03 \pm 0.06$ \\
7. & Neck length (horizontal) & 1079 & $0.05 \pm 0.07$ \\
8. & Body length & 1165 & $0.05 \pm 0.09$ \\
9. & Tail length & 942 & $0.41 \pm 0.09$ \\
10. & Tail diameter at base & 1165 & $0.28 \pm 0.091$ \\
11. & Height at sacrum & 1133 & $0.11 \pm 0.09$ \\
12. & Rump length & 1168 & $0.13 \pm 0.08$ \\
\hline
\end{tabular}

The least square means \pm SD for head related measurements i.e included head length, horn diameter at base, length of ear, ear width and poll width were $54.13 \pm 3.48, \quad 18.65 \pm 2.06, \quad 29.5 \pm 2.12, \quad 18.66 \pm 1.22$ and 
$30.95 \pm 2.35 \mathrm{~cm}$, respectively. Average values for neck length and neck circumference were observed as $53.32 \pm 4.56$ and $95.77 \pm 8.58 \mathrm{~cm}$, respectively. The least square meas $\pm \mathrm{SD}$ for height at sacrum and horizontal body length were $135.77 \pm 4.4 \mathrm{~cm}$ and $139.56 \pm 6.29 \mathrm{~cm}$, respectively. The length of tail and its diameter at base was measured and its value averaged $103.51 \pm 12.55$, $22.41 \pm 2.005 \mathrm{~cm}$, respectively. Mean value for rump length was observed as $43.52 \pm 2.582 \mathrm{~cm}$.

Heritability estimates of body measurements: The univariate animal model heritability estimates for body measurement traits are presented in table 3. The heritability estimates for most of the body measurements have been found in low to modium range. It indicates that most of the variation in traits was due to environmental effects and additive genetic effect has very low role to play. The lowest heritability was found for neck circumference $(0.03 \pm 0.06)$ and highest estimate was for tail length $0.41 \pm 0.09$. The heritability estimates for tail diameter at base $(0.28 \pm 0.091)$ and ear length $(0.38 \pm 0.04)$ fall in medium to high range.

\section{DISCUSSION}

\section{Body measurements}

Head length: The measurement of head length obtained in the current study was found as $54.13 \pm 3.48 \mathrm{~cm}$. The means values for the face length of Nili Ravi buffaloes as $55 \mathrm{~cm}$ (Shah and Hussain, 1953), for Banni Buffalo breed as $53.7 \pm 0.20 \mathrm{~cm}$ (Mishra et al., 2009) are not very different from present study means. Vohra et al. (2015) reported head length as $48.58 \pm 0.11$ in lesser known buffaloes of north India. Sahu et al. (2017) reported head length as $49.47 \pm 0.41 \mathrm{~cm}$ in Sambalpuri buffaloes. These buffaloes are of riverine types and could be compared with NIli-Ravi buffaloes. The mean head length as $42.9 \pm 2.6 \mathrm{~cm}$ reported by Campanile et al. (2003) for Italian Buffaloes which are of meditarreanian type and $47 \pm 0.1 \mathrm{~cm}$ for Chilika Buffaloes (Patro et al., 2003) are low than present study values. Kalita et al. (2010) reported $51.27 \pm 0.38 \mathrm{~cm}$ head length in Swamp buffaloes. It looks that Nili Ravi buffaloes posses longer head as compared many other breeds.

Poll width: Nili Ravi is a riverine type buffaloe. These buffaloes vary in body structure and face and head shape from Swamp bufflaoes. Their comparison could not be justified. However the poll width reported for Swamp buffaloes of Assam is $19.01 \pm 0.31 \mathrm{~cm}$ which is less than present study estimate. Breed differences might be the reason.

Horn diameter at base: An average estimate of $18.65 \pm 2.06 \mathrm{~cm}$ for horn diameter at base has been observed in Nili Ravi buffaloes. Almost similar value $(19.82 \pm 0.12 \mathrm{~cm})$ was reported by Vohra et al. (2015) for lesser known buffaloes (Bubalus Bubalis) of north India. Berthouly et al. (2010) and Kalita et al. (2010) have reported an average estimte of horn diameter at base in Swamp buffaloes as $23.2 \pm 0.4$ and $29.17 \pm 0.49 \mathrm{~cm}$, respectively. It looks that horns of the swamp buffaloes are thicker at base as compared to Nili Ravi buffaloes included in current study.

Ear length: The means values reported for ear length of Banni buffaloes $29.3 \pm 0.1 \mathrm{~cm}$ (Mishra et al., 2009) and lesser known buffaloes of India (Bubalus Bubalis) $28.76 \pm 0.09 \mathrm{~cm}$ (Vohra et al., 2015) are of similar magnitude as for this study. However the ear length $26 \pm 0.1 \mathrm{~cm}$ for Chilika buffaloes reported by Patro et al. (2003) is less than current study mean value for ear length. Yakubu et al. (2009) has reported an ear length of $17.57 \pm 0.27 \mathrm{~cm}$ in White Fulani cows. Khan et al. (2018) in a study on Sahiwal cows has documented an average estimate of ear length as $25.6 \pm 1.70 \mathrm{~cm}$. The reason for differences from the current study could be the species difference.

Ear width: Shah and Hussain (1953) have reported ear width as 18.17 and $18.18 \mathrm{~cm}$ in Nili and in Ravi breed, respectively which is in agreement to current study means. The Nili and Ravi breeds are parents of Nili Ravi Buffaloes. So there is no difference for ear width as reported in these studies. Khan et al. (2009) has reported ear width as $16.2 \pm 0.15 \mathrm{~cm}$ in AzaKheli buffaloes. In a study on Sahiwal cows, Khan et al. (2018) has described ear width as $15.8 \pm 0.89 \mathrm{~cm}$. Pundir et al. (2011) has also reported a similar value as $16.10 \pm 0.05$ in Kankrej cows. All these findings vary from the findings of the current study and the reason could be due to species, breed, herd, year, age and other environmental differences.

Neck circumference: The lean neck is considered as dairy character. The farmers have preferences for the buflaoes with long and thin neck. Long and thin neck is an indicative of good milk producing ability. While going through the literature, it has been observed that very scanty documented information is available for buffaloes as concern neck circumference. Some of the studies have reported neck circumference in different breeds of cattle. The neck circumference reported for Siri breed of cattle $70 \pm 0.9 \mathrm{~cm}$ (Phangchung and Roden, 1996) and $73.21 \pm 0.32$ for Kankrej cattle (Pundir et al., 2011) are very low as compared to present study mean values. The species differences could be one the reason for this variation.

Neck length: Neck length adds to beauty of dairy animals. It is an important component of dairy character. Shah and Hussain (1953) have reported neck length as 51.45 and $53 \mathrm{~cm}$ in Nili and in Ravi breed, respectively. This is in consensus with present study findings because of common origin of the breeds. However the mean values as reported by Patro et al. (2003) in Chilika 
Buffaloes and Prasad and Kumar (2005) in Tarai buffaloes $60 \pm 0.1 \mathrm{~cm}$ and $63 \mathrm{~cm}$, respectively are higher than current study means. The trait definition could be one of the causes of difference. In present study the neck length was taken as horizontal distance from first thoracic vertebra to center of poll where as in some other studies it is taken as flapping distance from anterior point of hump to poll (Khan et al., 2018). Khan et al. (2009) documented a score of $42.0 \pm 0.48 \mathrm{~cm}$ in AzaKheli buffaloes. Pundir et al. (2011) has reported an average neck length of $50.63 \pm 0.18 \mathrm{~cm}$ in Kankrej cows which slightly coincide with the findings of the current study. Aamir et al. (2010) has reported this value as $43.04 \pm 0.07$ $\mathrm{cm}$ in Kenana cattle. In case of Sahiwal cows, Khan et al. (2018) has reported an estimate of $37.4 \pm 4.90$ for this trait. The differences of traits definition and breed and species could be important.

Body length: In present study, the least squares means for body length in Nili Ravi buffaloes was found as $139.56 \pm 6.29 \mathrm{~cm}$. Khan et al. (2009) and Khan (2009) has reproetd body length for AziKheli and Bhadwari Buffloaes of same magnitude as in present study $139.0 \pm 1.32 \mathrm{~cm}$ and $139 \mathrm{~cm}$, respectively. Lower estimates have been documented as $121 \pm 1 \mathrm{~cm}$ and $122 \pm 0.2 \mathrm{~cm}$ in Iranian and Chilika Buffaloes by Dezfuli et al. (2010) and Patro et al. (2003), respectively and Sahu et al. (2017) reported body length as $128.76 \pm 0.86$ in Sambalpuri buffaloes. Vohra et al. (2015) reported body length as $133.33 \pm 0.35 \mathrm{~cm}$ in lesser known buffaloes of north India. Higher means values have been reported by Andrea et al. (2010) as $142 \pm 8 \mathrm{~cm}$ and Djaja (2011) as $147.98 \pm 8.96 \mathrm{~cm}$ in Murrah Buffaloes, Mishra et al. (2009) as $153.7 \pm 0.4 \mathrm{~cm}$ in Banni Buffaloes, Campanile et al. (2003) as $146.2 \pm 7.9 \mathrm{~cm}$ in Italian Buffaloes, Mehboob (1996) as 151.6 \pm 8.7 , Khalid (2013) as $147.3 \pm 7.2 \mathrm{~cm}$, and Ahmad et al. (2013) $147.3 \pm 7.2$, respectively in Nili Ravi Buffaloes and Kalita et al. (2010) as $142.22 \pm 0.67$ $\mathrm{cm}$ in Swamp buffaloes. The breed differences might be the main cause for such variation. Amongst other trait definition is very important. Some of the studies report this trait as diagonal body lenth from point of shoulder to pin bone where as others recorded as horizontal distance from wither to the pin bone at dorsal side of the body.

Tail length: The means reported for Nili Ravi buffaloes by Mehboob (1996) as $104.65 \pm 16.26 \mathrm{~cm}$ and for Iraqi buffaloes as $106.0 \pm 0.9 \mathrm{~cm}$ (Avadesian et al., 2017) are similar to current study mean. Slightly higher than present study means were reported by Shah and Hussain (1953) as 108 and $115 \mathrm{~cm}$ in Nili and in Ravi breed, respectively. All other estimates in various buffalo breeds are comparatively less from this breed and included $90.57 \pm 1.15 \mathrm{~cm}$ in lesser known buffaloes of north India (Vohra et al., 2015), $71.9 \pm 1.61 \mathrm{~cm}$ in AzaKheli buffaloes (Khan et al., 2009), $88.4 \pm 0.53 \mathrm{~cm}$ in Banni Buffaloes (Mishra et al., 2009), 68 $\pm 0.2 \mathrm{~cm}$ in Chilika Buffaloes
(Patro et al., 2003) and 79.19 $0.56 \mathrm{~cm}$ in Swamp buffaloes (Kalita et al., 2010). Sahu et al. (2017) reported tail length as $81.33 \pm 0.90 \mathrm{~cm}$ in Sambalpuri buffaloes. The present study results vary due to breed, herd, age and other environmental differences.

Tail diameter at base: Diameter of tail at its base has been found as $22.41 \pm 2.01 \mathrm{~cm}$ in Nili Ravi buffaloes in the current study. Alsiddig et al. (2010) has reported width of tail base instead of diameter as $7.15 \pm 0.08 \mathrm{~cm}$ and $6.37 \pm 0.13 \mathrm{~cm}$ in Nyalawi and Mesairi cattle, respectively. The results of these findings are not comparable with the findings of current study.

Height at sacrum: The traits related to height and bone conformation in the current study showed a smaller variation with coefficient of variation ranging from 3.24 to 3.75 . Average value of $135.77 \pm 4.40 \mathrm{~cm}$ for height at sacrum has been observed in the present study. Ahmad et al. (2013) reported body height as $140.2 \pm 7.2 \mathrm{~cm}$, in Nili Ravi Buffaloes. Campanile et al. (2003) reported an average estimate of $139.2 \pm 4.1 \mathrm{~cm}$ for this trait in Italian Buffaloes. Negretti et al. (2008) and Andrea et al. (2010) have reported average height at sacrum as $139.7 \pm 4.3 \mathrm{~cm}$ and $1.39 \pm 0.04 \mathrm{~m}$ in Mediterranean Buffaloes and Murrah Buffaloes, respectively. Bhooshan et al. (2016) reported height at sacrum as $141.30 \pm 0.38 \mathrm{~cm}$ in graded Murrah buffaloes. These findings are not in agreement with the findings of the current study and the reason may be due to breed, herd, age and other environmental differences.

Rump length: Mean value for rump length in Nili Ravi buffaloes was found as $43.52 \pm 2.58 \mathrm{~cm}$. Almost similar findings have been reported by Negretti et al. (2008) as 44.9 \pm 2.6 in Mediterranean Buffaloes and by Andrea et al. (2010) as $0.45 \pm 0.03 \mathrm{~m}$ in Murrah Buffaloes. The findings of the current study are slightly higher than the values reported by Prasad and Kumar (2005) in Tarai buffaloes as $40 \mathrm{~cm}$ and by Khan et al. (2009) in AzaKheli buffaloes as $41.4 \pm 0.45 \mathrm{~cm}$. Campanile et al. (2003) has reported a rump length of $46.8 \pm 3.2 \mathrm{~cm}$ in Italian Buffaloes. The variations in the results are due to anatomical differences among the breeds and might be due to herd, age and other managemental differences.

Heritability estimates for head and neck related traits: In general the heritability estimates for most of the traits were in low range. It means that the traits were mostly being effected by non genetic reasons. Among the non genetic reason, the scorer variation, the traits definitions and facilities available at difeent stations for restraining of animals while recording observation might be important resaons. The authenticity of pedigree record could affect the heritability estimates. It has been observed in general that buffloes do not feel comfortable while taking measurements thus affecting the recording. However the traits like head length, ear length, tail length 
and tail diameter have heritability estimates in medium to high range.

Khan et al. (2018) has reported a higher heritability estimates for ear length, ear width and neck length as $0.68 \pm 0.03, \quad 0.75 \pm 0.02$ and $0.52 \pm 0.04$ respectively in Sahiwal cows. Lower than current study the heritability estimate $0.10 \pm 0.03$ of head length was reported for Holstein cows (Smith et al., 1985). Some traits have higher genetic control as compared to others hence they showed higher heritabilities. Many other studies have reported higher heritability estimates for body lenth contrary to current study estimates. Brum and Ludwick (1969) and Lin et al. (1987) have reported heritability estimates for body length as $0.47 \pm 0.08$ and $0.91 \pm 0.07$, respectively in Holstein Friesian cows. Andoyo et al. (2012) has reported heritability estimate for body length as $0.38 \pm 0.08$ in Bali cattle. Khan et al. (2018) has reported heritability estimate for body length as $0.81 \pm 0.02$ in Sahiwal cows. The species-breed differences and small data set and recording parcatices might have influences the estimation of additive genetic variance and hence affected the estimates.

Similar trend of estimates has been found for body length where heritabilities are reported in higher range $0.58 \pm 0.014$ for Czech Fleckvieh cattle (Novotny et al., 2017) and $0.83 \pm 0.02$ for Sahiwal cows (Khan et al., 2018). However heritability estimate for height at hip bone of Holstein cows was in low range 0.20 (Shanks and Spahr, 1982) but even higher than current study estimate.

The maximum value of heritability estimate among all the body measurements has been observed for tail length as $0.41 \pm 0.09$. Khan et al. (2018) has reported corresponding value as $0.95 \pm 0.01$ which is very high and does not coincide with the findings of current study. Heritability estimate for tail diameter was observed slightly low as $0.28 \pm 0.091$ in the current study. Heritability estimate for tail length was based on 942 records while that of tail diameter was based on 1165 records. Relatively less number of records for tail length were due to tail injuries in buffaloes resulting in the cutting of tails. Selection for tail length will be effective however, animal with longer tails mostly suffer from tail injuries.

The heritability estimate for rump length was found as $0.13 \pm 0.08$. Smothers et al. (1993), Larroque et al. (1999) and Daliri et al. (2008) have reported heritability estimates for rump length as $0.19,0.29$ and $0.23 \pm 0.013$, respectively. Novotny et al. (2017) has reported heritability estimate for rump length as $0.26 \pm 0.012$ in Czech Fleckvieh cattle. Corresponding value for this trait was reported as $0.76 \pm 0.02$ by Khan et al. (2018) which does not match with current study estimates. Trait definition is one of the important factors for this variation. Because in some studies, the rump length is the distance between top most positions of the hook bones and some other studies have said as distance between outer most positions on lateral sides of the hook bone.

Conclusions: Generally, the least squares means for most of the body measurements were found in the normal range and were in agreement with most of the reports in literature. Most of the body measurements were affected by the herd and age factors but the effect of parity, stage of lactation and season of scoring was variable for different traits and showed not very clear trend. Most of the body measurements have been found to be lowly to moderately heritable in the current study.

Acknowledgements: The cooperation of farm incharges of livestock experiment stations in Punjab to conduct this research is highly acknowledged. The funding for this research was provided by the Higher Education Commission of Pakistan under the 5000-Ph.D fellowship program.

\section{REFERENCES}

Aamir, H. M., S. A. Babikar, G. M. Youssif, and Y. A. Hassan (2010). Phenotypic characterization of Sudanese Kenana cattle. Res. J. Anim. Vet. Sci. 5:43-47.

Ahmad, N., M. Abdullah, K. Javed, M.S. Khalid, M.E. Babar, U. Younas and Nasrullah (2013). Relationship between Body Measurements and Milk Production in Nili-RaviBuffaloes Maintained at Commercial Farms in Peri-Urban Vicinity of Lahore. Buff. Bullet.32 (Special Issue 2): 792-795.

Alsiddig, M.A., S.A. Babikar, M.Y. Galal and A.M. Mohammed (2010). Phenotypic characterization of Sudan zebu cattle (Baggara type). Res. J. Anim. Vet. Sci. 5: 10-17.

Andrea, M.V., R.S. Cerqueira,C.R. Marcondes,C.M. Macedo junior, D.R. Santos and K.N. Oliveira (2010). Correlations between linear measurements and milk production in Murrah Buffaloes. Proceedings of the $9^{\text {th }}$ World Buffalo congress, Argentina.351-353.

Andoyo, S., M. Tomiyama and K. Suzuki (2012). Estimation of (Co)Variance Components and Genetic Parameter of Withers Height, Chest Girth and Body Length of Bali Cattle Using Animal Model. Intl. J. of Molecular Zool., 2(5): 45-50.

Avadesian, G., A. Al-Hadad, W.M. Razuki, N.N. AlAnbari, M. Aswadi and A.S. Sadiq (2017). Effects of parity and location on body dimensional measurements in Iraqi buffaloes at Southern: a case study at al-Nasiriyah Governorate. Buff. Bullet.36 (2):297-305. 
Berthouly, C., X. Rognon, T.Nhu Van, A. Berthouly, H. Thanh Hoang, B. BedHom, D. Laloe, C.Vu Chi, E.Verrier and J.C. Maillard (2010). Genetic and morphometric characterization of a local Vietnamese Swamp buffalo population. J. Anim. Breed. \& Genet. 127 (1): 74-84.

Bhooshan, K.S., S. Mishra and A. Dubey (2016). Appraisal of linear type traits in graded Murrah buffaloes. Buff. Bullet.35(2): 291-298.

Brum, E.W. and T.M. Ludwick (1969). Heritabilities of certain immature and mature body measurements and their correlations with first lactation production of Holstein cows. J. Dairy Sci. 52: 352-358.

Campanile, G., R. Dil Palo, C. De Rosa, V. Peretti, L. Amante, F. Ciotola and A. Coletta (2003). Preliminary results on Mediterranean Italian buffalo morfometry. Ital. J. Anim. Sci. 2 (Suppl. 1): 337-339.

Daliri, Z.S., H. Hafezian, A. Shad Parvar and G.Rahimi (2008). Genetic relationship among longevity, milk production and linear type traits in Iranian Holstein cattle. J. Anim. Vet. Advances 7 (4): 512-515.

Dezfuli, B.T., M. Babaee, M. R. Mashayekhi and S.S. Sofia (2010). Prediction of live weight from linear body measuremets in Iranian buffaloes. Advances in Anim. Bio. sci. 1 (1): 277.

Djaja,W. (2011). An introduction study on characterstics of body length, withers height and body weight of Murrah female buffalo in Deli Serdang and Serdang bengali county, north Sumatra province. lucraristiintifice 55, 213-216.

FAO. (2012). Phenotypic characterization of animal genetic resources. FAO Animal Production and Health Guidelines No. 11. Rome

Gilmour, A.R., B.J. Gujel, B.R. Cullis and R. Thompson. (2009). ASReml User Guide (Version 3.0), VSN International Ltd, Hemel Hempstead, HP1 1ES, UK.

Javed, K., M. Abdullah, M. S. Khalid, N. Ahmad, J. A. Bhatti and U. Younas. (2013). Inter-relationship of Milk Constituents with Body and Udder Measurements in Nili-Ravi Buffaloes Raised at Commercial Farms of Pakistan. Buff. Bullet. (32) (Special Issue 2): 1170-1173.

Kalita, R., A. Dandapat, B.D.C. Kamal, G.C. Das and R.N. Goswami. (2010). Conformation traits of Swamp buffalo of Assam at different age groups. Ind. J. Anim. Res. 44(4): 300-302.

Khan, M.S., A. Nazir and M.A. Khan (2007). Genetic resources and diversity in dairy buffaloes of Pakistan. Pakistan Vet. J. 27(4): 201-207.

Khan, S. A., M. S. Khan, Y. Muhammad, S. Sultan, F. Muhammad, S. A. Khan and G. Jabbar (2009).
On-Farm performance of Azikheli buffalo. Pakistan J. Zool. Suppl. ser. No 9:209-212.

Khan, M. A. (2009). Buffalo the Animal of Future, $1^{\text {st }}$ Edition, Idara Matbuaat-e-Sulemania, Lahore, Pakistan.

Khan, M. A., M. S. Khan and A. Waheed (2018). Morphological measurements and their heritability for Sahiwal cattle in Pakistan. The J. Anim. Plant Sci. 28(2):431-440.

Larroque, H., R. Rupp, S. Moureaux, D. Boichard and V. Ducrocq (1999). Genetic parameters for type and functional traits in the French Holstein breed. Interbull Bulletin 23:1-13.

Lin, C.Y., A.J. Lee, A.J. Mcallister, T.R. Batra, G. L. Roy, J. A.Vesely, J.M. Wauthy and K.A. Winter (1987). Intercorrelations among milk production traits and body and udder measurements in Holstein heifers. J. Dairy Sci. 70:2385-2393.

Mehboob-ur-Rehman (1996). Studies on phenotypic characteristics and body conformation of Nili Ravi buffaloes and their relationship with milk production.M.Sc. thesis, University of Agriculture, Faisalabad, Pakistan.

Mirza, R. H., K. Javed, A. Maqsood, R. Mubashar, M.A. Khan, M.A. Tipu and S.M. Raihan Dilshad (2015). Environmental factors affecting linear classification of top line and feet and leg traits in Nili Ravi Buffaloes of Pakistan. J. Agri. Engineering and Biotech., 3: 84-91.

Mishra, B.P., K.P. Singh, D.B. Chavan, D.K. Sadana, R.S. Kataria, P. Kathiravan and S.P.S. Ahlawat (2009). Characterization of Banni buffalo of Western India. AGRI 44:77-86.

Negretti, P., G. Bianconi, S. Bartocci , S. Terramoccia and M. Verna. (2008). Determination of live weight and body condition score in lactating Mediterranean buffalo by Visual Image Analysis: a Review article. Lives. Sci. 113 (1):17.

Novotny, L., J. Frelich, J. Beran and L. Zavadilova (2017). Genetic relationship between type traits, number of lactations initiated, and lifetime milk performance in Czech Fleckvieh cattle. Czech J. Anim. Sci., 62, 501-510.

Patro, B.N., P.K. Mishra and P.K. Rao (2003). Chilika buffaloes in Orissa: a unique germplasm. Anim. Genetic Resources Infor. 33: 73-79.

Patterson, H.D.and R. Thompson (1971). Recovery of inter-block information when block size are unequal. Biometrica. 52: 545-554.

Phangchung and J.A. Roden (1996). Characterization of Siri breed and the Mithun cross Siri breed in Bhutan. AGRI, 20: 27-34.

Prasad, R.B. and S. Kumar (2005). Phenotypic characterization of Tarai buffalo breed. Buffalo Newsletter 21:9-10. 
Pundir, R.K., P.K. Singh, K.P. Singh and P.S. Dangi (2011). Factor analysis of biometric traits of kankrej cows to explain body conformation. Asian Aust. J. Anim. Sci. 24(4): 449-456.

Sahu, S., G.D. Nayak and D.K. Karna (2017). Phenotypic characteristics of Sambalpuri buffaloes of India. Buff. Bullet.36(4) 615-621.

SAS Instt.Inc. (2011). SAS/STAT user's guide, Release 9.3. Carry, North Carolina, USA.

Shah, S.M.A. and S.M. Hussain (1953). Nili breed of buffaloes. Bullet. No. 3. Animal Husbandry Department, Punjab, Pakistan.

Shanks, R.D. and S.L. Spahr (1982). Relationship among udder depth, hip height, hip width and daily milk production in Holstein cows. J. Dairy Sci. 65: 1771-1775.

Smith, S.P., F.R Allaire, W.R. Taylor, W.R. Kaeser and J. Conley (1985). Genetic parameters and environmental factors associated with type traits scored on an ordered scale during second and fourth lactation. J. Dairy Sci. 68:2655-2663.

Smothers, C.D., R.E. Pearson, I. Hoeschele and D.A. Funk (1993). Herd final score and its relationship to genetic and environmental parameters of conformation traits of United States Holstein. J. Dairy Sci. 76:1671-1677.

Vohra, V., S.K. Niranjan, A.K. Mishra, V. Jamuna1, A. Chopra1, N. Sharma, and Dong KeeJeong (2015). Phenotypic Characterization and Multivariate Analysis to ExplainBody Conformation in Lesser Known Buffalo (Bubalusbubalis) from North India.Asian Australas. J. Anim. Sci. 28 (3): 311-317.

Yakubu, A., D.M.Ogah and K.O. Idahor (2009). Principal component analysis of the morpho structural indices of white Fulani cattle. Trakia J. Sci. 7(2):67-73. 